\title{
Accuracy of identifying incident stroke cases from linked health care data in UK Biobank
}

Kristiina Rannikmäe, PhD,* Kenneth Ngoh,* Kathryn Bush,* Rustam Al-Shahi Salman, PhD, Fergus Doubal, PhD, Robin Flaig, David E. Henshall, Aidan Hutchison, John Nolan, Scott Osborne, Neshika Samarasekera, PhD, Christian Schnier, PhD, Will Whiteley, PhD, Tim Wilkinson, Kirsty Wilson, Rebecca Woodfield, PhD, Qiuli Zhang, PhD, Naomi Allen, PhD, and Cathie L.M. Sudlow, PhD

Neurology ${ }^{\circledR}$ 2020;95:e697-e707. doi:10.1212/WNL.0000000000009924

\section{Abstract \\ Objective}

In UK Biobank (UKB), a large population-based prospective study, cases of many diseases are ascertained through linkage to routinely collected, coded national health datasets. We assessed the accuracy of these for identifying incident strokes.

\section{Methods}

In a regional UKB subpopulation $(\mathrm{n}=17,249)$, we identified all participants with $\geq 1$ code signifying a first stroke after recruitment (incident stroke-coded cases) in linked hospital admission, primary care, or death record data. Stroke physicians reviewed their full electronic patient records (EPRs) and generated reference standard diagnoses. We evaluated the number and proportion of cases that were true-positives (i.e., positive predictive value [PPV]) for all codes combined and by code source and type.

\section{Results}

Of 232 incident stroke-coded cases, 97\% had EPR information available. Data sources were $30 \%$ hospital admission only, $39 \%$ primary care only, $28 \%$ hospital and primary care, and $3 \%$ death records only. While $42 \%$ of cases were coded as unspecified stroke type, review of EPRs enabled a pathologic type to be assigned in $>99 \%$. PPVs ( $95 \%$ confidence intervals) were $79 \%$ $(73 \%-84 \%)$ for any stroke ( $89 \%$ for hospital admission codes, $80 \%$ for primary care codes) and $83 \%$ (74\%-90\%) for ischemic stroke. PPVs for small numbers of death record and hemorrhagic stroke codes were low but imprecise.

\section{Conclusions}

Stroke and ischemic stroke cases in UKB can be ascertained through linked health datasets with sufficient accuracy for many research studies. Further work is needed to understand the accuracy of death record and hemorrhagic stroke codes and to develop scalable approaches for better identifying stroke types.

\author{
Correspondence \\ Dr. Rannikmäe \\ kristiina.rannikmae@ \\ ed.ac.uk
}

\section{RELATED ARTICLE}

\section{Comment}

Can we trust administrative codes for identification of stroke cases?

Page 250

\footnotetext{
*These authors contributed equally to this work.

From the Centre for Medical Informatics, Usher Institute of Population Health Sciences and Informatics (K.R., K.B., R.F., A.H., J.N., C.S., T.W., K.W., Q.Z., C.L.M.S.), and Centre for Clinical Brain Sciences (R.A.-S.S., F.D., N.S., W.W., R.W.), University of Edinburgh; UK Biobank (K.R., K.B., R.F., A.H., J.N., C.S., T.W., K.W., R.W., Q.Z., N.A., C.L.M.S.), Stockport; University of Edinburgh Medical School (K.N., D.E.H., S.O.); and Nuffield Department of Population Health (N.A.), University of Oxford, UK.

Go to Neurology.org/N for full disclosures. Funding information and disclosures deemed relevant by the authors, if any, are provided at the end of the article. 


\section{Glossary}

$\mathbf{C I}=$ confidence interval; $\mathbf{E P R}=$ electronic patient record; $\mathbf{I C D}=$ International Classification of Diseases; $\mathbf{I C H}=$ intracerebral hemorrhage; PPV = positive predictive value; $\mathbf{S A H}=$ subarachnoid hemorrhage; UKB = UK Biobank.

Stroke is the second commonest cause of death worldwide and a major global cause of disability. ${ }^{1}$ Very large prospective population-based studies are needed to improve our understanding of its risk factors and causal associations. ${ }^{2}$

UK Biobank (UKB) is a prospective population-based cohort study with extensive phenotypic and genotypic information on $>500,000$ participants from England, Scotland, and Wales (ukbiobank.ac.uk). It is an open-access resource, established to facilitate research into the determinants of a wide range of health outcomes, particularly those of relevance in middle and older age. ${ }^{3}$

A cost-effective way of following UKB participants for disease outcomes is via linkages to routinely collected, coded, national administrative health datasets. UKB receives regularly updated linkages to national hospital admission and death record data for all participants, and to primary care data for a large and increasing subset. However, appropriate use of these data in research studies requires understanding of their accuracy. In a systematic review of published studies, we found that stroke-specific diagnosis codes in hospital admission and death record data generally have good accuracy. However, the studies varied widely in their settings and methodology, with very limited data about the accuracy of primary care codes or the effect of combining different data sources. ${ }^{4}$

We therefore conducted a validation study to assess the accuracy of ascertainment of incident stroke cases in UKB via linked coded national administrative health datasets (including primary care data), compared with diagnoses assigned following adjudication by clinical experts with access to the full free-text electronic patient records (EPRs).

\section{Methods}

\section{Study population}

We conducted the study in a subpopulation of 17,249 UKB participants in the Lothian region of southeast Scotland, all of whom are linked to national administrative health datasets (including hospital, primary care, and death record codes). This region encompasses the city of Edinburgh, where one of UKB's recruitment centers was located. Within this subpopulation, we identified all those with at least one code in their linked health data that indicated a stroke diagnosis after their recruitment to UKB.

\section{Stroke definition}

We defined stroke according to the WHO definition: "rapidly developing clinical signs of focal (or global) disturbance of cerebral function, lasting more than 24 hours or leading to death, with no apparent cause other than that of vascular origin."

\section{Code selection and sources}

We selected and included relevant codes from hospital admission, primary care, and death records up to the end of September 2015, the date at which data were complete for all sources at the time of this study.

In the United Kingdom, hospital admissions and death records are coded by specialized medical coders, who use the International Classification of Diseases (ICD; currently version 10) coding system to assign a primary code to the main condition resulting in a particular admitted episode of care, and secondary codes to other conditions. Primary care data are coded by general practice clinical or administrative staff during clinical encounters or on receipt of information from elsewhere (e.g., hospital inpatient and specialist outpatient settings).

Primary care data in the United Kingdom currently use the Read coding system (version 2 in Scotland during the time period of relevance in this study).

We selected relevant stroke codes from the ICD-10 and Read version 2 coding systems, aiming to ascertain cases of stroke with a high positive predictive value (PPV) (i.e., to minimize the proportion of false-positives among the stroke cases), while aiming to ascertain as many as possible of the true cases (i.e., optimizing sensitivity). Our code selections were informed by the results of a systematic review, ${ }^{4}$ browsing of the Technology Reference Data Update Distribution Service (isd.hscic.gov.uk/ trud3/user/guest/group/0/home), the Secure Anonymised Information Linkage databank cerebrovascular diseases dictionary, ${ }^{6}$ the Quality Outcomes Framework indicator sets for stroke (www.wales.nhs.uk/), and the CALIBER online data portal (www.caliberresearch.org/), as well as manual review of code lists by experts (table e-1, dryad.org/10.5061/dryad.w9ghx3fk0).

We only validated diagnoses for cases with their first incident stroke, defined as the first-ever-in-a-lifetime occurrence of a WHO-defined stroke according to codes from linked national administrative datasets. We excluded participants who self-reported a stroke at baseline recruitment or who had a stroke code in their linked health care data predating recruitment to UKB. This was because (1) incident disease cases (i.e., new-onset disease arising in those without a history of the relevant condition) are of most research interest in a prospective, population-based study recruiting mainly healthy volunteers and (2) a large proportion of stroke cases identified through codes or self-reported stroke status arising prior to recruitment (prevalent cases) predated the EPR system used for validation. We based our analyses on the earliest code(s) for each participant from any data source. 


\section{Process of assigning an expert diagnosis}

For each included participant with a stroke code, we extracted, anonymized, and created a single document (hereafter referred to as a "vignette") from all available relevant medical information from the secondary care EPR system, including outpatient clinic letters, hospital discharge summaries, and formal radiologic investigation reports (figure e-1, dryad.org/ 10.5061/dryad.w9ghx3fk0). We considered information relevant if it was associated with a hospital admission leading to the code, or if it was within 2 months before or after the date of a relevant primary care code. A 2-month window was chosen to reflect local clinical practice during the time period of the study: patients in NHS Lothian with a suspected stroke or TIA not requiring hospital admission would have been referred to the neurovascular specialist outpatient clinic, where they would usually be seen within 1 week, in keeping with national guidelines (the National Institute for Health and Care Excellence guidance, www.nice.org.uk/guidance/cg68, and the Scottish Stroke Care Audit Standards, strokeaudit.scot.nhs.uk/ Quality/Scottish_Stroke_Care_Standards.html).

Following this specialist clinic visit, correspondence to the patient's general practitioner would generally appear on the secondary care EPR system within days to a few weeks, providing the clinical information required to validate primary care codes.

We developed an adjudication form, which included a summary for adjudicators of criteria for the diagnosis of stroke, its pathologic types (ischemic stroke, intracerebral hemorrhage $[\mathrm{ICH}]$, subarachnoid hemorrhage $[\mathrm{SAH}]$ ), and subtypes (appendix e-1, dryad.org/10.5061/dryad.w9ghx3fk0).

Six consultant stroke specialists (hereafter referred to as "adjudicators") completed adjudication forms based on the information in the EPR-derived vignettes. They did not have access to review the brain imaging themselves, but formal scan reports were included in the vignettes. One adjudicator (K.R.) completed the forms for all participants and 5 other adjudicators (N.S., C.S., R.A.-S.S., F.D., W.W.) independently completed the forms (each for a subset) to allow assessment of interadjudicator agreement. All adjudicators were blinded to which specific codes had led to ascertainment of any case and to each other's diagnoses. The first adjudicator's diagnoses were used as the reference standard for the primary analyses in this study.

\section{Data analyses}

\section{Participants' characteristics}

We summarized participants' sex and median age at recruitment and at the time the code was assigned.

\section{Code source and type identification}

We calculated the number and proportion of stroke-coded participants arising from each data source. We also stratified the codes into those specifying a stroke type (ischemic vs ICH vs $\mathrm{SAH}$ ) vs those indicating an unspecified type of stroke, and calculated the numbers and proportions of these arising from each source. We compared these findings with the same analyses for the larger subset of all UKB participants with linkage to the relevant data sources in England, Scotland, and Wales.

\section{Assessment of interadjudicator agreement}

We used percent agreement and Cohen kappa $(\kappa)^{7}$ to measure interadjudicator agreement, comparing one adjudicator's (K.R.) diagnoses with a second (one of N.S., C.S., R.A.-S.S., F.D., W.W.) for the following: stroke vs not; stroke/TIA vs not; and, in cases where both adjudicators agreed that the diagnosis was stroke, ischemic stroke vs ICH vs SAH vs uncertain stroke type.

\section{Calculating code accuracy}

The main measure of accuracy assessed in this study was PPV (the proportion of all stroke-coded cases ascertained that were true-positive cases). While we could not directly assess sensitivity, we were able to assess the effects on both PPV and the number of true-positive cases (a higher number of truepositives indicates higher sensitivity) of different code combination strategies for ascertaining cases. We categorized the stroke-coded cases as true-or false-positives based on adjudicators' diagnoses. We calculated the PPV and its 95\% confidence interval (CI) using the Clopper Pearson exact method, considering both (1) only an adjudicator diagnosis of stroke a true-positive and (2) an adjudicator diagnosis of stroke or TIA a true-positive. To understand the contribution of each source of codes, we calculated PPVs for each code source separately (hospital admission vs primary care vs death record data) and for their combinations, and explored the effect (both on PPV and on true-positive case numbers) of including only codes in the primary position for hospital admission data.

We also calculated PPVs for ischemic and hemorrhagic stroke types, and explored the effect (both on PPV and on truepositive case numbers) of restricting hospital data to codes in the primary position and of treating all unspecified stroke type codes as ischemic stroke codes.

In further analyses, we assessed administrative vs overall code accuracy and the effect on resulting PPVs, as we hypothesized that this may explain some of the variability of the results among previous validation studies. Some validation studies are based on the assumption that if the diagnostic code reflects the diagnosis mentioned somewhere in the EPR (often, for example, the discharge summary for a particular hospital admission), then this is sufficient to confirm the accuracy of the code. ${ }^{4}$ We refer to this as the administrative accuracy of the code. Clinicians will, however, appreciate that assessing the accuracy of a diagnostic code is more nuanced. A patient's true diagnosis may emerge over time after encounters with several different clinicians with varying levels of expertise and with access to different amounts of relevant information; hence, the EPR can contain inconsistencies, which may require specialist clinical knowledge to detect and/or resolve. Hence a specialist 


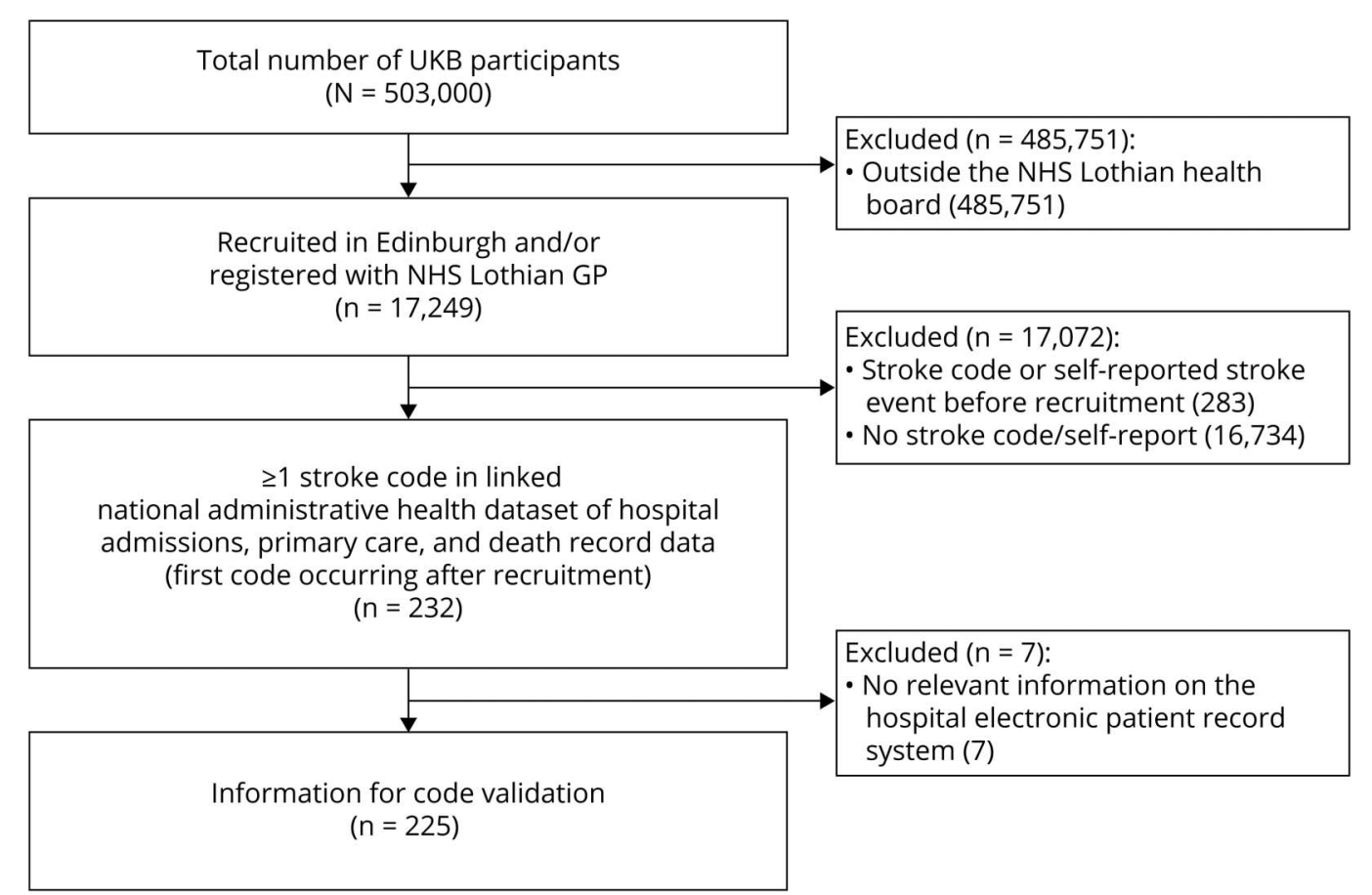

GP = general practitioner; NHS = National Health Service.

physician's review of all relevant parts of the complete EPR will give a more accurate picture of the true diagnosis and so of the code accuracy, which we refer to as the overall accuracy. We assessed administrative accuracy by having a primary care physician in our team review the EPR-derived vignettes for mentions of stroke diagnoses. We assessed overall accuracy by having expert adjudicators (consultant level stroke specialists) review the EPR-derived vignettes and derive reference standard diagnoses based on all available information and their clinical interpretation of this information (see Process of assigning an expert diagnosis). We then assessed whether, and by how much, the administrative vs overall accuracy (PPV) differed for our selected stroke codes.

We performed all statistical analyses in R (r-project.org).

\section{Further exploration of false-positive codes}

We compared characteristics of participants with a true- vs a false-positive code and reviewed the vignettes of falsepositive cases, considering their alternative diagnoses and assessing possible reasons for them being assigned a stroke code. Informed by these assessments, we evaluated alternative code combinations that we hypothesized may improve code accuracy.

\section{Stroke type and subtype distributions}

We further assessed the proportion of true-positive cases that could be assigned a pathologic stroke type (ischemic stroke, $\mathrm{ICH}, \mathrm{SAH}$ ) and more detailed subtype by the stroke specialist adjudicator, and their frequency distributions.

\section{Standard protocol approvals, registrations, and patient consents}

All procedures performed in studies involving human participants were in accordance with the ethical standards of the institutional and/or national research committee and with the 1964 Helsinki declaration and its later amendments or comparable ethical standards. As part of the UKB recruitment process, informed consent was obtained from all individual participants included in the study.

\section{Data availability}

Anonymized summary data based on this study not published within this article can be shared (subject to approval from $\mathrm{UKB}$ ) on request from any qualified investigator unless limited by ethical or legal restrictions. Any bona fide researcher can access the UKB resource for research that aims to benefit the public's health (see ukbiobank.ac.uk).

\section{Results}

\section{Study population}

In the subpopulation of 17,249 participants, 232 had a relevant stroke code occurring after recruitment to UKB. Of these, 225 (97\%) had available information in their EPR to create a vignette and were included in the study analyses (figure 1).

\section{Participants' characteristics}

Of the 225 stroke-coded cases, 111 (49\%) were female. Median age at recruitment to UKB was 63 years (range 41-70 
Table 1 Participant characteristics

\begin{tabular}{llll}
\hline & All coded cases $(\mathbf{n}=\mathbf{2 2 5})$ & True-positive cases $(\mathbf{n}=\mathbf{1 7 8})$ & False-positive cases $(\mathbf{n}=\mathbf{4 7})$ \\
\hline Female & $49(111 / 225)$ & $47(84 / 178)$ & $57(27 / 47)$ \\
\hline Recruitment age, $\mathbf{y}$ & $63(41-70)$ & $63(41-70)$ & $64(46-69)$ \\
\hline Age at code, $\mathbf{y}$ & $67(45-76)$ & $67(45-76)$ & $67(52-76)$ \\
\hline Primary care code only & $33(75 / 225)$ & $26(47 / 178)$ & $60(28 / 47)$ \\
\hline Unspecified stroke code & $42(86 / 225)$ & $38(68 / 178)$ & $38(18 / 47)$ \\
\hline Hemorrhagic stroke code & $22(49 / 225)$ & $20(35 / 178)$ & $30(14 / 47)$ \\
\hline Code date <2011 & $34(76 / 225)$ & $33(58 / 178)$ & $38(18 / 47)$ \\
\hline Dead by end of follow-up (any cause) & $8(18 / 225)$ & $7(13 / 178)$ & $11(5 / 47)$ \\
\hline
\end{tabular}

Values are $\%(n)$ or median (range).

years) and at time of the stroke code was 67 years (range $45-76$ years) (table 1 ).

\section{Code sources and types}

Of the 225 stroke-coded cases, 67 (30\%) received a code from hospital admission data only, 87 (39\%) from primary care data only, 64 (28\%) from both hospital admission and primary care data, 6 (3\%) from death records only, and one from both hospital admission data and death records (table 2 and figure e-2, dryad.org/10.5061/dryad.w9ghx3fk0). For the larger subset of all UKB participants with linkage to the relevant data sources, these proportions were similar for Scotland, but a higher proportion of participants in England and Wales had hospital-only codes (table 2).
As regards stroke types, 131/225 (58\%) of stroke-coded cases had a stroke type-specific code (ischemic, ICH, or SAH), while the remaining 94 (42\%) had unspecified stroke codes. The proportion of cases with unspecified stroke type codes was higher among those ascertained from primary care (105/ $151[70 \%])$ than from hospital admission data (38/132 [29\%]), and all death record codes were stroke-type specific (for these code-source level estimates, a case would be counted $\geq 1$ if occurring in $\geq 1$ source) (table 3 and figure e- 2 , dryad.org/10.5061/dryad.w9ghx3fk0). Among the larger subset of all UKB participants with relevant linked data, the proportion of cases with an unspecified stroke code was similar for Scotland, but lower for England and Wales (19\% and $30 \%$, respectively) (table 3 ).

Table 2 Code sources in the validation study subpopulation and in the larger subset of all UK Biobank (UKB) participants linked to relevant health care datasets in Scotland, England, and Wales

\begin{tabular}{|c|c|c|c|c|}
\hline & $\begin{array}{l}\text { UKB participants, Scotland, } \\
\text { Lothian }(n=17,249)\end{array}$ & $\begin{array}{l}\text { UKB participants, } \\
\text { Scotland, all }^{a}(n=31,426)\end{array}$ & $\begin{array}{l}\text { UKB participants, } \\
\text { England, all }{ }^{\mathrm{a}}(n=18,494)\end{array}$ & $\begin{array}{l}\text { UKB participants, } \\
\text { Wales, all }^{\mathrm{a}}(\mathrm{n}=21,346)\end{array}$ \\
\hline Total stroke codes & 225 & 553 & 197 & 301 \\
\hline Hospital only codes & $30(67 / 225)$ & $27(147 / 553)$ & $42(82 / 197)$ & $43(129 / 301)$ \\
\hline Primary care only codes & $39(87 / 225)$ & $44(241 / 553)$ & $29(58 / 197)$ & $39(116 / 301)$ \\
\hline Death record only codes & $3(6 / 225)$ & $1(7 / 553)$ & $0(0 / 197)$ & $3(10 / 301)$ \\
\hline $\begin{array}{l}\text { Hospital and primary care } \\
\text { codes }\end{array}$ & $28(64 / 225)$ & $28(156 / 553)$ & $29(57 / 197)$ & $14(43 / 301)$ \\
\hline $\begin{array}{l}\text { Hospital and death record } \\
\text { codes }\end{array}$ & $0(1 / 225)$ & $0(2 / 553)$ & $0(0 / 197)$ & $1(2 / 301)$ \\
\hline $\begin{array}{l}\text { Primary care and death } \\
\text { record codes }\end{array}$ & $0(0 / 225)$ & $0(0 / 553)$ & $0(0 / 197)$ & $0(0 / 301)$ \\
\hline $\begin{array}{l}\text { Hospital and primary care } \\
\text { and death record codes }\end{array}$ & $0(0 / 225)$ & $0(0 / 553)$ & $0(0 / 197)$ & $0(1 / 301)$ \\
\hline
\end{tabular}

a We included UKB participants with linkage to hospital admissions data, death records, and primary care data (whereas around half of UKB participants are linked to primary care data using Read V2 or V3 coding systems, we included only practices using the Read V2 coding system for ease of comparison). 
Table 3 Proportion of cases with unspecified vs specified stroke type codes in the validation study subpopulation and in the larger subset of all UK Biobank (UKB) participants linked to relevant health care datasets in Scotland, England, and Wales

\begin{tabular}{lllll}
\hline & $\begin{array}{l}\text { UKB participants, Scotland, } \\
\text { Lothian }(\mathbf{n = 1 7 , 2 4 9 )}\end{array}$ & $\begin{array}{l}\text { UKB participants, } \\
\text { Scotland, all }(\mathbf{n = 3 1 , 4 2 6 )}\end{array}$ & $\begin{array}{l}\text { UKB participants, England, } \\
\text { all }^{\mathbf{a}}(\mathbf{n = 1 8 , 4 9 4 )}\end{array}$ & $\begin{array}{l}\text { UKB participants, Wales, } \\
\text { alla }^{\mathbf{a}}(\mathbf{n = 2 1 , 3 4 6})\end{array}$ \\
\hline Total stroke codes & 225 & 553 & 197 & 301 \\
\hline $\begin{array}{l}\text { Unspecified codes in } \\
\text { hospital data }\end{array}$ & $29(38 / 132)$ & $27(81 / 305)$ & $7(10 / 139)$ & $17(30 / 175)$ \\
\hline $\begin{array}{l}\text { Unspecified codes in } \\
\text { primary care }\end{array}$ & $70(105 / 151)$ & $64(254 / 397)$ & $45(52 / 115)$ & $50(80 / 160)$ \\
\hline $\begin{array}{l}\text { Unspecified codes in } \\
\text { death records }\end{array}$ & $0(0 / 7)$ & $11(1 / 9)$ & $n / a$ & $54(7 / 13)$ \\
\hline $\begin{array}{l}\text { Unspecified codes } \\
\text { total }\end{array}$ & $42(94 / 225)$ & $40(219 / 553)$ & $19(37 / 197)$ & $30(89 / 301)$ \\
\hline
\end{tabular}

Values are $\%(n)$

a We included UKB participants with linkage to hospital admissions data, death records, and primary care data (whereas around half of UKB participants are linked to primary care data using Read V2 or V3 coding systems, we included only practices using the Read V2 coding system for ease of comparison).

b \% Stroke-coded cases with an unspecified stroke type code (note that if a case has codes from multiple sources, including a specified stroke type code in hospital data and an unspecified stroke type code in primary care data or death record data, they will count as having a specified code).

\section{Interadjudicator agreement}

All vignettes were independently reviewed by 2 adjudicators. For assigning a diagnosis of stroke vs not, interadjudicator agreement was $91 \%$ and Cohen kappa very good at 0.7 (95\% CI, 0.6-0.8); for stroke/TIA vs not, agreement was $93 \%$ and Cohen kappa very good at 0.7 (95\% CI, 0.6-0.9). Agreement for assigning a stroke type (ischemic stroke vs $\mathrm{ICH}$ vs $\mathrm{SAH}$ vs uncertain stroke type) was 99\% and Cohen kappa excellent at 0.98 (95\% CI, 0.9-1).

\section{Code accuracy}

The overall PPV of case ascertainment for all 225 strokecoded cases from all sources combined was 79\% (95\% CI, $73 \%-84 \%)$. When broken down by code source, PPV was highest for the 132 cases with hospital admission codes (89\%; 95\% CI, 82\%-94\%), and higher still when limiting analyses to primary position hospital codes only $(94 \%$; $95 \%$ CI, $88 \%-98 \%)$, at the expense of losing a few $(<10 \%)$ truepositive cases. PPV for the 151 cases with primary care codes was $80 \%$ (95\% CI, $72 \%-86 \%$ ). Only 7 cases had death record codes, with PPV 57\% (95\% CI, 18\%-90\%), the wide CIs indicating limited precision of this estimate. For cases with both a hospital admission and a primary care code, PPV was very high (97\%; 95\% CI, $89 \%-100 \%)$, but only a third of the cases fell into this category (figure $2 \mathrm{~A}$ ).

As regards the accuracy of identifying stroke pathologic type (for these estimates, a case would be counted in $\geq 1$ analysis if it had $\geq 1$ unique stroke type code), PPV among the 88 participants with an ischemic stroke code was $83 \%$ (95\% CI, $74 \%-90 \%$ ); restricting to primary position codes (for those cases from hospital admission data) increased this to $86 \%$ (95\% CI, $76 \%-93 \%$ ), with loss of $<10 \%$ of true-positive cases (figure $2 \mathrm{~B})$. Given that ischemic stroke is the most common pathologic stroke type, and hence an unspecified stroke code is much more likely to signify an ischemic rather than a hemorrhagic stroke case, we calculated the PPV for ischemic stroke of the 184 ischemic and unspecified stroke codes combined. While this resulted in a slightly lower PPV of $80 \%$ (95\% CI, $73 \%-85 \%)$, it approximately doubled the number of truepositive ischemic stroke cases identified. The proportion of true-positive ischemic stroke cases among all cases with an unspecified code was $77 \%$. Accuracy of hemorrhagic stroke codes was lower but the small numbers of coded cases resulted in limited precision: PPV among 26 participants with an ICH code was $42 \%$ (95\% CI, 23\%-63\%) and among 24 participants with a SAH code was $71 \%$ (95\% CI, 49\%-87\%). Restricting to primary position codes increased the PPV of both ICH and $\mathrm{SAH}$ codes without losing any true-positive cases.

PPV when measuring only administrative accuracy was $93 \%$, decreasing to $79 \%$ when measuring overall accuracy. This demonstrates the importance of expert-led adjudication in validation studies, as ignoring it would lead to falsely inflated PPVs (figure 3).

\section{Further exploration of false-positive codes}

The 47 false-positive stroke-coded cases had a similar proportion of unspecified codes and median age (at date of recruitment or first stroke code) as true-positives. False-positive cases were more likely to have a primary care code and to have died by the end of follow-up, and were slightly more likely to be female, to have a hemorrhagic stroke code, and to have an earlier first stroke code date (table 1).

Alternative diagnoses for the 47 false-positives included TIA $(14 / 47,30 \%)$; secondary intracranial bleed not due to SAH or $\mathrm{ICH}$ (e.g., traumatic, tumor-related, bleeding into a cerebral infarct) (11/47 [23\%]); radiologic finding of a suspected old vascular lesion (usually incidental) $(8 / 47[17 \%])$; and possible or probable alternative diagnosis (e.g., migraine, demyelination, seizure, or another diagnosis) $(14 / 47[30 \%])$. 
Figure 2 Positive predictive values (PPVs) of stroke codes

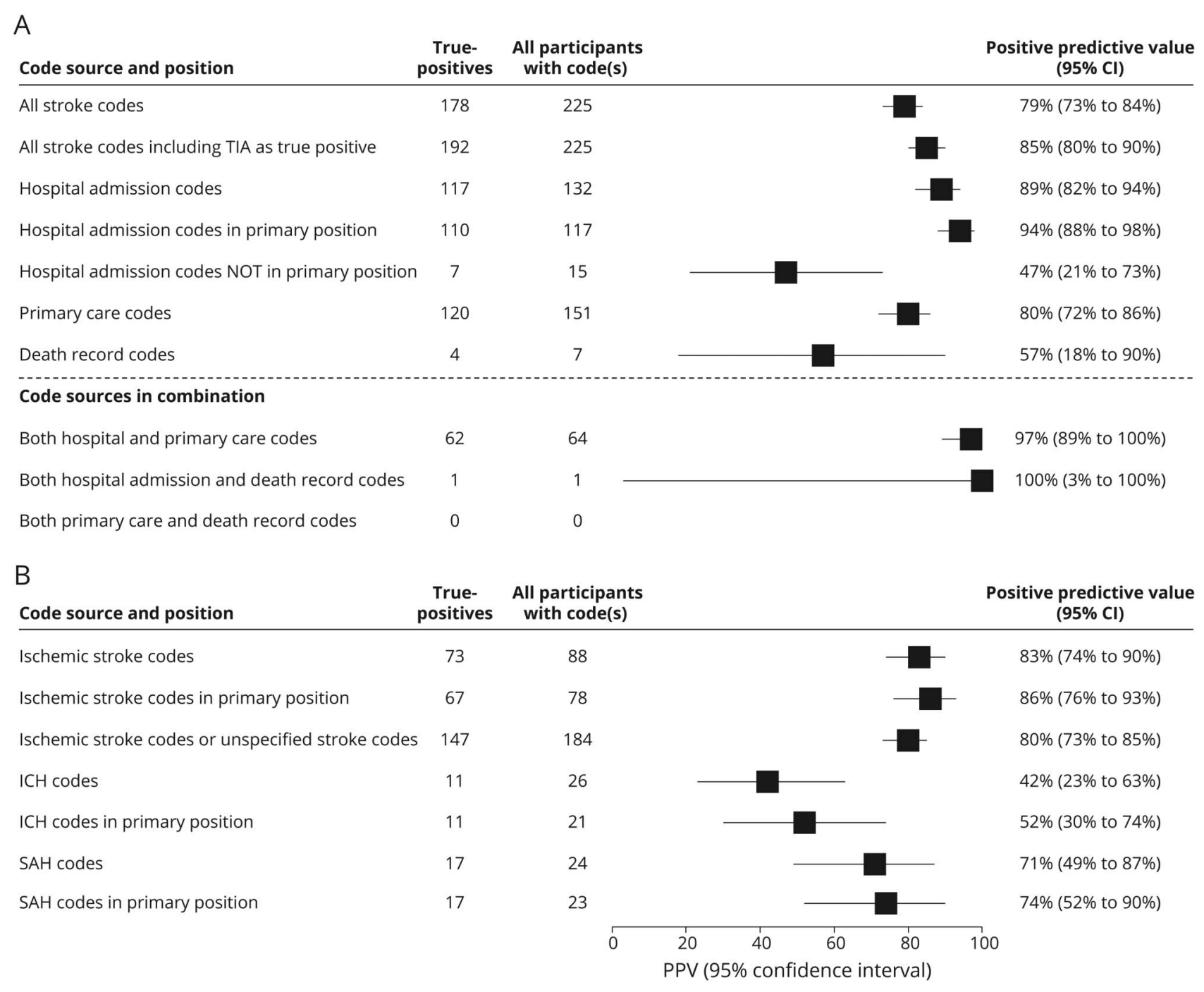

PPVs of stroke codes stratified by code source (A) and code type (B). Primary position: includes primary care codes, where no code position is specified, and only primary position hospital admission codes. $\mathrm{Cl}$ = confidence interval; ICH = intracerebral hemorrhage; $\mathrm{SAH}=$ subarachnoid hemorrhage.

Among the 15 participants with a false-positive ICH code, $7 / 15$ had another primary stroke type \pm secondary ICH, $4 / 15$ intratumor bleed, $3 / 15$ traumatic or other intracranial bleed, and $1 / 15$ no obvious reason for an ICH code. Among the 7 participants with a false-positive $\mathrm{SAH}$ code, $4 / 7$ were traumatic intracranial bleed, $2 / 7$ another primary stroke type \pm secondary $\mathrm{SAH}$ component, and 1/7 asymptomatic aneurysm.

Because performance for hemorrhagic stroke codes was suboptimal, having observed that the more common alternative diagnoses were traumatic and intratumor bleeds or stroke complicated by a bleed, we performed additional analyses to explore the effects of different code inclusion criteria on numbers of cases, numbers of true-positives, and PPV for ICH and SAH. For both ICH and SAH, we could increase PPV but at the expense of failing to detect some truepositive cases. However, numbers of cases were too small to draw firm conclusions (figure 4).

\section{Stroke type and subtype distributions}

With information from the EPR, a stroke specialist was able to assign a pathologic stroke type to 177 of the 178 true-positive stroke cases: 149 (84\%) were ischemic, 11 (6\%) ICH, and 17 (10\%) SAH. Depending on the subclassification system used, an ischemic subtype could be determined for $37 \%-87 \%$ of cases, an ICH subtype for $27 \%-100 \%$ of cases, and SAH subtype for $94 \%$ of cases (figure e-3, dryad.org/10.5061/ dryad.w9ghx3fk0).

\section{Discussion}

Our results suggest that stroke cases, and cases of ischemic stroke type, can be ascertained in UKB through linked coded data with sufficient accuracy for use in many genetic and epidemiologic research studies without further expert validation, since PPVs were generally at least $80 \%$ despite 
Figure 3 Assessing administrative vs overall accuracy

\begin{tabular}{lccc}
\hline Reference standard diagnosis & $\begin{array}{c}\text { True- } \\
\text { positives }\end{array}$ & $\begin{array}{c}\text { All participants } \\
\text { with code(s) }\end{array}$ & $\begin{array}{c}\text { Positive predictive value } \\
(95 \% \mathrm{Cl})\end{array}$ \\
\hline
\end{tabular}

\section{Administrative accuracy}

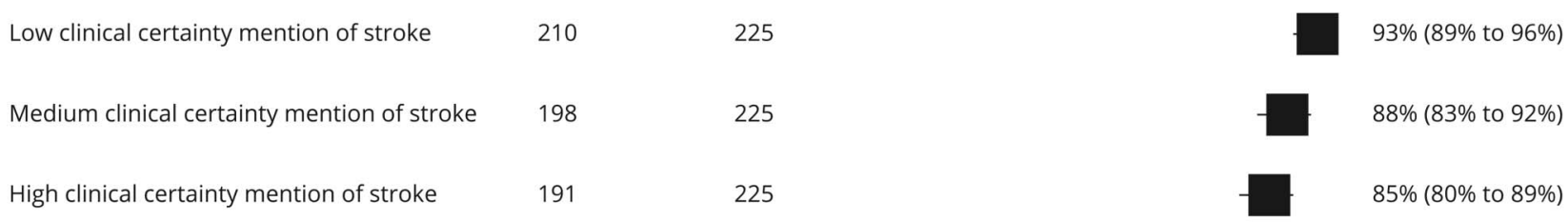

\section{Overall accuracy}

Expert adjudicator diagnosis of stroke

\begin{tabular}{|c|c|c|c|c|}
\hline 0 & 20 & 40 & 60 & 80 \\
\hline
\end{tabular}

High clinical certainty mentions of stroke: "stroke," "probable stroke," "presumptive stroke," "consistent with stroke," "compatible with stroke," "likely stroke," "treated as stroke" or equivalent stroke terms (ICH, SAH, intracerebral hemorrhage, subarachnoid hemorrhage, ischemic stroke, infarct). Medium clinical certainty mentions of stroke: including above plus "possible stroke," "suspected stroke," "impression of stroke," "suggestive of stroke," "query stroke," or equivalent stroke terms (ICH, SAH, intracerebral hemorrhage, subarachnoid hemorrhage, ischemic stroke, infarct). Low clinical certainty mentions of stroke include above plus "TIA" and "transient ischaemic attack" with any level of certainty preceding it. The hierarchy of clinical certainty was based on the ICD-10 clinical coding instruction manual (isdscotland.org/Products-and-Services/Terminology-Services/Clinical-Coding- Guidelines/, April 2010 version), which is used by the coding departments in UK hospitals. $\mathrm{Cl}=$ confidence interval; PPV = positive predictive value.

stringent adjudication criteria. Primary care is an important code source with $\geq 1 / 3$ of the cases ascertained exclusively via primary care data in this UK setting. Code accuracy appeared slightly better for hospital admission compared to primary care codes. There were insufficient data to draw firm conclusions regarding the accuracy of death record or hemorrhagic stroke type codes. Including only the primary position codes from hospital admission data increased PPV without loss of a substantial proportion of true-positive cases. In the subpopulation of Scotland studied, only around $60 \%$ of codes were specific for a stroke type; however, using all available relevant medical information from the EPR, an expert adjudicator could assign a stroke type to $99 \%$, and a more detailed stroke subtype to between a third and almost $90 \%$ of cases, depending on the subclassification system used. A higher proportion of participants had a specified stroke type code in the English and Welsh data, but the accuracy of these codes needs further investigation. We also demonstrated that, at least in this setting, considering only the administrative accuracy of stroke diagnosis codes (rather than overall accuracy based on an expert review of the full EPR) may give falsely inflated PPVs.

Acceptable levels of accuracy, and the relative importance of different accuracy metrics, depend on the context. ${ }^{8} \mathrm{UKB}$ is primarily used for research into the genetic and nongenetic determinants of disease. ${ }^{3}$ In such analyses, it is important to ensure that a high proportion of participants identified as disease cases truly do have the disease (high
PPV) to minimize bias in effect estimates, while aiming to optimize statistical power by ascertaining as many truepositive cases as possible (optimizing sensitivity, but not necessarily maximizing it, as this may compromise the PPV). A high specificity (the proportion of participants without the disease that do not receive a stroke code) is crucial in obtaining a high PPV, but is not sufficient in and of itself. In population-based prospective cohorts where the proportion of all participants who are true-positives for the disease (in this case stroke) is generally low, the proportion of all participants incorrectly classified as having stroke (false-positives) will generally be low (giving high specificity), even if the absolute number of false-positives is high compared to the absolute number of true-positives (low PPV). ${ }^{8}$ Providing appropriate codes are used, both the specificity and negative predictive value of routinely collected health care data to identify disease cases in population-based studies are usually very high (96\%-100\%). ${ }^{4}$ For these reasons, we focused on estimating the PPV of using routinely collected health care data to identify stroke cases in UKB, and on assessing the effects of different code and source selections on both PPV and number of true-positive cases.

Strengths of this study include (1) the overall large number of participants; (2) inclusion of primary care and death record codes for which accuracy data have previously been limited; (3) creation of vignettes using preset criteria from the EPR for $97 \%$ of otherwise eligible stroke-coded cases, thus avoiding 
Figure 4 Exploratory analyses to improve accuracy of hemorrhagic stroke codes

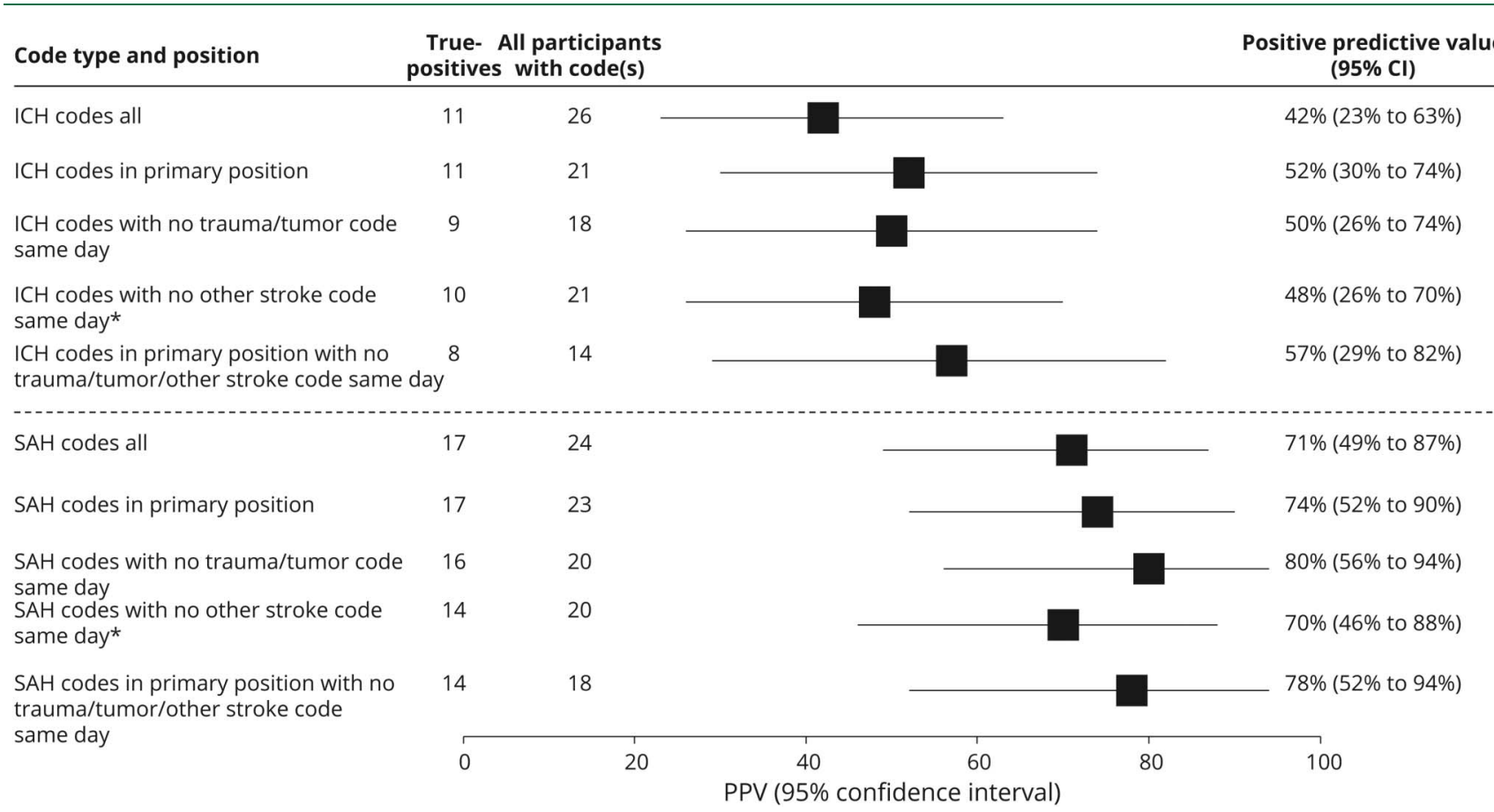

*Excluding other stroke code same day: excluded cases with a diagnostic code for $>1$ stroke pathologic type on the same day. This was done because a patient who has one pathologic stroke type (e.g., ischemic stroke) can sometimes develop a complication and subsequent brain scan appearances similar to another pathologic stroke type (e.g., a patient with ischemic stroke can have a bleed in the brain as a result of the ischemic stroke, which could lead to a false diagnosis of an intracerebral hemorrhage $[\mathrm{ICH}])$. $\mathrm{Cl}$ = confidence interval; PPV = positive predictive value; SAH = subarachnoid hemorrhage.

the bias of selecting participants with a higher prior probability of having had a stroke; (4) blinding of adjudicators to codes and each other's diagnoses; (5) assessment of interadjudicator reliability; (6) further analysis of false-positive codes; and (7) assessment of both administrative and overall accuracy, demonstrating the importance of an expert-led reference standard in validation studies.

There are some limitations: (1) small numbers precluded robust conclusions about the accuracy of death record and hemorrhagic stroke codes; (2) our lack of access to the full free text EPRs held exclusively by the primary care system may have led to slightly more conservative PPV estimates (although we would not expect this to be a major issue for stroke), as almost all stroke cases have acute inpatient or outpatient management in secondary care (in keeping with this is that we were able to find secondary care records for $97 \%$ of the cases) and information provided from primary to secondary care was available in the hospital EPR; (3) the potential difficulty in differentiating between definite falsepositive and uncertain cases from retrospective review of medical records, which may have further reduced the estimated PPVs; and (4) the restriction of the current study to a Scottish subpopulation of the UKB participants (although we have no reason to suspect substantial variation in the results considering that the code generation process across the United Kingdom follows similar pathways and given the broadly similar distribution of code sources in the wider UKB population across England, Scotland, and Wales).

The present study is limited to validating the accuracy of codes for symptomatic stroke (as defined by the WHO). Subclinical cerebrovascular disease (such as that detected by brain imaging), which is more common, particularly in older people, ${ }^{9}$ would not be readily ascertained by the linked, coded health care data sources used to follow the health of UKB participants, but can be detected through brain imaging conducted as part of the UKB multimodal imaging study of 100,000 of its participants.

These results are largely consistent with those from our earlier systematic review, ${ }^{4}$ where PPVs for stroke-specific ICD-10 hospital admission codes ranged from $79 \%$ to $83 \%,{ }^{10,11}$ and for ischemic stroke from $86 \%$ to $88 \% .^{10,12,13}$ Our results for $\mathrm{ICH}$ and SAH code accuracy among a small number of participants were worse than those from the 2 previous United Kingdom-based studies of ICD-10 or Read codes. ${ }^{13,14}$ This may be in part because these studies checked only (or mainly) for administrative accuracy, hence inflating the PPVs. Our results were similar to a Danish study, which also used an expert review of medical records to check for overall accuracy. ${ }^{10}$ To our knowledge, there are no previous validation studies of stroke-specific UK primary care Read codes or death record codes for diagnosis of all types of stroke, nor of the effect of combining primary care and hospital admission coded data. 
Further work will be required to further explore the accuracy of hemorrhagic stroke and death record codes in larger numbers of cases by expanding this work to other UKB recruitment locations, which will also enable assessment of the generalizability of these results to other regions of the United Kingdom. In our Scottish subpopulation, while over one-third of the codes were not specific for a stroke type, expert adjudication allowed a stroke type to be assigned for almost all cases. Future studies should investigate ways of automating this process, as well as methods for determining more detailed stroke subtypes.

Our results suggest that stroke and ischemic stroke cases in UKB can be identified through linked coded data with sufficient accuracy for many genetic and epidemiologic studies, while there are currently insufficient data to draw definite conclusions about the accuracy of hemorrhagic stroke codes.

\section{Acknowledgment}

The authors thank the UK Biobank participants; UK Biobank scientific, project, and data management teams in Oxford, Stockport, and Edinburgh; and the UK Biobank stroke outcomes working group (Oxford University: Valerie Beral, Yiping Chen, Zhengming Chen, Jane Green, Mary Kroll, Sarah Lewington, Peter Rothwell, Lucy Wright; Edinburgh University: Martin Dennis, Joanna Wardlaw, Sarah Wild). This research was awarded the University of Edinburgh Arthur Fonville prize.

\section{Study funding}

This work was supported by salary from UK Biobank and Health Data Research UK (HDRUK) fellowship (K.R.); salary from Dementias Platform UK (DPUK) clinical fellowship (K.B.); salary from Medical Research Council Clinical Research Training Fellowship (MR/P001823/1) (T.W.); salary from UK Biobank and DPUK (R.F., C.S.); salary from UK Biobank (K.W., R.W., Q.Z.); and salary from UK Biobank, Scottish Funding Council, DPUK, and HDRUK (C.L.M.S.) (Chief Scientist for UK Biobank). Project management and administration funding provided by UK Biobank.

\section{Disclosure}

K. Rannikmäe, K. Ngoh, K. Bush, R. Salman, F. Doubal, R. Flaig, D. Henshall, A. Hutchison, J. Nolan, S. Osborne, N. Samarasekera, C. Schnier, W. Whiteley, T. Wilkinson, K. Wilson, R. Woodfield, and Q. Zhang report no disclosures relevant to the manuscript. N. Allen was senior epidemiologist when this study was conducted. C. Sudlow was chief scientist for the UK Biobank study when this study was conducted. Go to Neurology.org/ $\mathrm{N}$ for full disclosures.

\section{Publication history}

Received by Neurology July 4, 2019. Accepted in final form January 27, 2020.
Appendix Authors

\begin{tabular}{lll}
\hline Name & Location & Contribution \\
\hline $\begin{array}{ll}\text { Kristiina } \\
\text { Rannikmäe, }\end{array}$ & $\begin{array}{l}\text { University } \\
\text { PhD }\end{array}$ & $\begin{array}{l}\text { Substantial contributions to the } \\
\text { conception and design of the work, } \\
\text { acquisition, analysis, and } \\
\text { interpretation of data }\end{array}$ \\
\hline
\end{tabular}

\begin{tabular}{lll}
\hline Kenneth Ngoh & $\begin{array}{l}\text { University } \\
\text { of } \\
\text { Edinburgh }\end{array}$ & $\begin{array}{l}\text { Substantial contributions to } \\
\text { acquisition, analysis, and } \\
\text { interpretation of data }\end{array}$ \\
\hline
\end{tabular}

\begin{tabular}{lll}
\hline Kathryn Bush University & $\begin{array}{l}\text { Substantial contributions to the } \\
\text { analysis and interpretation of }\end{array}$
\end{tabular}
of analysis and interpretation of data Edinburgh

\begin{tabular}{lll}
\hline $\begin{array}{l}\text { Rustam Al- } \\
\text { Shahi Salman, } \\
\text { PhD }\end{array}$ & $\begin{array}{l}\text { University } \\
\text { of } \\
\text { Edinburgh }\end{array}$ & $\begin{array}{l}\text { Substantial contributions to the } \\
\text { acquisition and interpretation of data }\end{array}$ \\
\hline $\begin{array}{l}\text { Fergus Doubal, } \\
\text { PhD }\end{array}$ & $\begin{array}{l}\text { University } \\
\text { of } \\
\text { Edinburgh }\end{array}$ & $\begin{array}{l}\text { Substantial contributions to the } \\
\text { acquisition and interpretation of data }\end{array}$ \\
\hline Robin Flaig & $\begin{array}{l}\text { University } \\
\text { of } \\
\text { Edinburgh }\end{array}$ & $\begin{array}{l}\text { Substantial contributions to the } \\
\text { acquisition and interpretation of data }\end{array}$ \\
& &
\end{tabular}

\begin{tabular}{lll}
\hline David E. & University & $\begin{array}{l}\text { Substantial contributions to the } \\
\text { acquisition and interpretation of data }\end{array}$ \\
Henshall & Edinburgh &
\end{tabular}

\begin{tabular}{lll}
\hline Aidan & University & Substantial contributions to the \\
Hutchison & of & acquisition and interpretation of data \\
& Edinburgh &
\end{tabular}

\begin{tabular}{lll}
\hline John Nolan & $\begin{array}{l}\text { University } \\
\text { of } \\
\text { Edinburgh }\end{array}$ & $\begin{array}{l}\text { Substantial contributions to the } \\
\text { acquisition and interpretation of data }\end{array}$ \\
\hline Scott Osborne & $\begin{array}{l}\text { University } \\
\text { of } \\
\text { Edinburgh }\end{array}$ & $\begin{array}{l}\text { Substantial contributions to the } \\
\text { acquisition and interpretation of data }\end{array}$ \\
\hline
\end{tabular}

\begin{tabular}{|c|c|c|}
\hline $\begin{array}{l}\text { Neshika } \\
\text { Samarasekera, } \\
\text { PhD }\end{array}$ & $\begin{array}{l}\text { University } \\
\text { of } \\
\text { Edinburgh }\end{array}$ & $\begin{array}{l}\text { Substantial contributions to the } \\
\text { acquisition and interpretation of data }\end{array}$ \\
\hline $\begin{array}{l}\text { Christian } \\
\text { Schnier, PhD }\end{array}$ & $\begin{array}{l}\text { University } \\
\text { of } \\
\text { Edinburgh }\end{array}$ & $\begin{array}{l}\text { Substantial contributions to the } \\
\text { acquisition and interpretation of data }\end{array}$ \\
\hline $\begin{array}{l}\text { Will Whiteley, } \\
\text { PhD }\end{array}$ & $\begin{array}{l}\text { University } \\
\text { of } \\
\text { Edinburgh }\end{array}$ & $\begin{array}{l}\text { Substantial contributions to the } \\
\text { acquisition and interpretation of data }\end{array}$ \\
\hline Tim Wilkinson & $\begin{array}{l}\text { University } \\
\text { of } \\
\text { Edinburgh }\end{array}$ & $\begin{array}{l}\text { Substantial contributions to the } \\
\text { conception and design of the work and } \\
\text { interpretation of data }\end{array}$ \\
\hline Kirsty Wilson & $\begin{array}{l}\text { University } \\
\text { of } \\
\text { Edinburgh }\end{array}$ & $\begin{array}{l}\text { Substantial contributions to the } \\
\text { acquisition and interpretation of data }\end{array}$ \\
\hline $\begin{array}{l}\text { Rebecca } \\
\text { Woodfield, PhD }\end{array}$ & $\begin{array}{l}\text { University } \\
\text { of } \\
\text { Edinburgh }\end{array}$ & $\begin{array}{l}\text { Substantial contributions to the } \\
\text { conception of the work and } \\
\text { interpretation of data }\end{array}$ \\
\hline $\begin{array}{l}\text { Qiuli Zhang, } \\
\text { PhD }\end{array}$ & $\begin{array}{l}\text { University } \\
\text { of } \\
\text { Edinburgh }\end{array}$ & $\begin{array}{l}\text { Substantial contributions to the } \\
\text { conception and design, acquisition, } \\
\text { analysis, and interpretation of data }\end{array}$ \\
\hline $\begin{array}{l}\text { Naomi Allen, } \\
\text { PhD }\end{array}$ & $\begin{array}{l}\text { University } \\
\text { of Oxford }\end{array}$ & $\begin{array}{l}\text { Substantial contributions to the } \\
\text { acquisition and interpretation of data }\end{array}$ \\
\hline $\begin{array}{l}\text { Cathie L.M. } \\
\text { Sudlow, PhD }\end{array}$ & $\begin{array}{l}\text { University } \\
\text { of } \\
\text { Edinburgh }\end{array}$ & $\begin{array}{l}\text { Substantial contributions to the } \\
\text { conception and design of the work, } \\
\text { acquisition and interpretation of data }\end{array}$ \\
\hline
\end{tabular}




\section{References}

1. Lozano R, Naghavi M, Foreman K, et al. Global and regional mortality from 235 causes of death for 20 age groups in 1990 and 2010: a systematic analysis for the Global Burden of Disease Study 2010. Lancet 2012;380:2095-2128.

2. Burton PR, Hansell AL, Fortier I, et al. Size matters: just how big is BIG? quantifying realistic sample size requirements for human genome epidemiology. Int J Epidemiol 2009:263-273.

3. Sudlow C, Gallacher J, Allen N, et al. UK Biobank: an open access resource for identifying the causes of a wide range of complex diseases of middle and old age. PLoS Med 2015;12:e1001779.

4. Woodfield R, Grant I, UK Biobank Stroke Outcomes Group, UK Biobank Follow-Up and Outcomes Working Group, Sudlow CL. Accuracy of electronic health record data for identifying stroke cases in large-scale epidemiological studies: a systematic review from the UK Biobank stroke outcomes group. PLoS One 2015;10:e0140533.

5. WHO MONICA Project Investigators. The World Health Organization MONICA project (Monitoring Trends and Determinants in Cardiovascular Disease). J Clin Epidemiol 1988;41:105-114.

6. Ford DV, Jones KH, Verplancke JP, et al. The SAIL Databank: building a national architecture for e-health research and evaluation. BMC Health Serv Res 2009;9:157.
7. Viera AJ, Garrett JM. Understanding interobserver agreement: the kappa statistic. Fam Med 2005;37:360-363.

8. Chubak J, Pocobelli G, Weiss NS. Tradeoffs between accuracy measures for electronic health care data algorithms. J Clin Epidemiol 2012;65:343-349.e2.

9. Kirkman MA, Mahattanakul W, Gregson BA, Mendelow AD. The accuracy of hospital discharge coding for hemorrhagic stroke. Acta Neurol Belg 2009;109:114-119.

10. Johnsen SP, Overvad K, Sørensen HT, Tjønneland A, Husted SE. Predictive value of stroke and transient ischemic attack discharge diagnoses in the Danish National Registry of Patients. J Clin Epidemiol 2002;55:602-607.

11. Krarup LH, Boysen G, Janjua H, Prescott E, Truelsen T. Validity of stroke diagnoses in a national register of patients. Neuroepidemiology 2007;28:150-154.

12. Haesebaert J, Termoz A, Polazzi S, et al. Can hospital discharge databases be used to follow ischemic stroke incidence? Stroke 2013;44:1770-1774.

13. Wright FL, Green J, Canoy D, et al. Vascular disease in women: comparison of diagnoses in hospital episode statistics and general practice records in England. BMC Med Res Methodol 2012;12:161.

14. Gaist D, Wallander MA, Gonzalez-Perez A, Garcia-Rodriguez L. Incidence of hemorrhagic stroke in the general population: validation of data from the Health Improvement Network. Pharmacoepidemiol Drug Saf 2013;22:176-182. 


\section{Neurology}

\section{Accuracy of identifying incident stroke cases from linked health care data in UK Biobank}

Kristiina Rannikmäe, Kenneth Ngoh, Kathryn Bush, et al.

Neurology 2020;95;e697-e707 Published Online before print July 2, 2020

DOI 10.1212/WNL.0000000000009924

This information is current as of July 2, 2020

\section{Updated Information \& Services}

References

Citations

Subspecialty Collections

Permissions \& Licensing

Reprints including high resolution figures, can be found at: http://n.neurology.org/content/95/6/e697.full

This article cites 13 articles, 1 of which you can access for free at: http://n.neurology.org/content/95/6/e697.full\#ref-list-1

This article has been cited by 1 HighWire-hosted articles: http://n.neurology.org/content/95/6/e697.full\#\#otherarticles

This article, along with others on similar topics, appears in the following collection(s):

All Cerebrovascular disease/Stroke

http://n.neurology.org/cgi/collection/all_cerebrovascular_disease_strok $\mathrm{e}$

\section{Cohort studies}

http://n.neurology.org/cgi/collection/cohort_studies

\section{Infarction}

http://n.neurology.org/cgi/collection/infarction

Intracerebral hemorrhage

http://n.neurology.org/cgi/collection/intracerebral_hemorrhage

Subarachnoid hemorrhage

http://n.neurology.org/cgi/collection/subarachnoid_hemorrhage

Information about reproducing this article in parts (figures,tables) or in its entirety can be found online at:

http://www.neurology.org/about/about_the_journal\#permissions

Information about ordering reprints can be found online:

http://n.neurology.org/subscribers/advertise

Neurology ${ }^{\circledR}$ is the official journal of the American Academy of Neurology. Published continuously since 1951, it is now a weekly with 48 issues per year. Copyright Copyright ( 2020 The Author(s). Published by Wolters Kluwer Health, Inc. on behalf of the American Academy of Neurology.. All rights reserved. Print ISSN: 0028-3878. Online ISSN: 1526-632X.

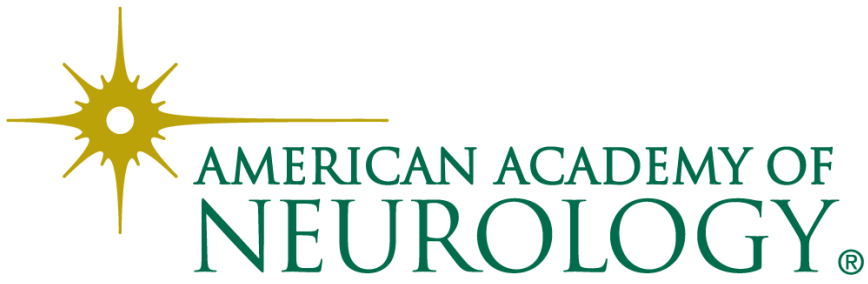

